\title{
Therapeutic effects of physostigmine during systemic inflammation
}

This article was published in the following Dove Press journal:
Journal of Inflammation Research

\author{
Katharina Effenberger- \\ Neidnicht ${ }^{\prime}$ \\ Johannes Jägers ${ }^{2}$ \\ Rabea Verhaegh' \\ Michael Kirsch' \\ 'Institute of Physiological Chemistry, \\ University Hospital Essen, Essen, \\ Germany; 'Institute of Physiology, \\ University Hospital Essen, Essen, \\ Germany
}

Introduction: Usually, physostigmine is used as antidote for anticholinergic poisons in order to improve hemodynamics and cardiac output. In addition, it causes beneficial effects during sepsis when added timely. Here, we studied whether physostigmine improves hemodynamics when treatment during systemic inflammation was delayed.

Methods: Two series of randomized studies with overall 44 rats were conducted. Systemic inflammation was induced by lipopolysaccharide (LPS) infusion ( $0.5 \mathrm{mg} \mathrm{LPS} / \mathrm{kg} \times \mathrm{h}$ ). Physostigmine (PHY) was intravenously applied after an LPS infusion period of 90 minutes (50 $\mu \mathrm{g}$ PHY $/ \mathrm{kg}$ within 10 minutes) with (series 1) and without (series 2) additional volume loading. Hemodynamic parameters, blood gases, and parameters for tissue damage were periodically determined for up to 180 minutes. Results: Even though volume was additionally administered (series 1), LPS caused a reduction of peripheral blood flow. Treatment with PHY improved hemodynamics in macrocirculation (mean arterial blood pressure) and microcirculation (peripheral blood flow). PHY neither affected alterations in blood gases, electrolyte homeostasis, and glucose metabolism nor prevented intestinal damage induced by LPS. In series 2, without any additional volume loading, PHY likewise resulted in an improvement of the LPS-induced alterations in macro- and microcirculation, but finally worsened the LPS-mediated effects on plasma parameters for tissue damage such as creatine kinase, probably due to the lack of volume and a further damage to the heart. Conclusion: The present results demonstrated that hemodynamic responses to PHY may not only be visible in patients with anticholinergic drug overdose but also be visible in septic patients, provided that fluid intake of these patients is adequate.

Keywords: sepsis, septic shock, lipopolysaccharide, peripheral blood flow, mean arterial blood pressure, volume load, serine, rat

\section{Introduction}

Despite all advances in intensive care medicine, sepsis, that illness is accompanied with a high mortality rate $(30 \%-50 \%)$, is the third leading cause of death in industrialized countries. ${ }^{1-3}$ Sepsis - recently defined as "life-threatening organ dysfunction caused by a dysregulated host response to an infection" 4,5 - is usually associated with an impairment of both macrocirculation (massive drop in blood pressure leading to shock) and microcirculation (lack of peripheral blood flow and tissue oxygenation), which in turn contributes to multiple organ failure and death.

The two most common animal models known to mimic human sepsis are the cecal ligation and puncture (CLP) model and the lipopolysaccharide (LPS, bacterial endotoxin) protocol. ${ }^{6,7}$ The LPS protocol induces a kind of systemic inflammation with an
Correspondence: Katharina

Effenberger-Neidnicht

Institute of Physiological Chemistry,

University Hospital Essen, Hufelandstraße

55, D-45I 22 Essen, Germany

Tel +4920I 7234103

Email katharina.effenberger-neidnicht@ uni-due.de 
early reduction of the peripheral blood flow, an increase of both mean arterial blood pressure and heart rate (HR) in order to compensate a failure in microcirculation (hyperdynamic phase), and a later massive drop in blood pressure (hypodynamic shock state). ${ }^{8}$

Physostigmine (PHY, also called eserine) is an alkaloid from the seeds of Physostigma venenosum, ${ }^{9}$ which can cross the blood-brain barrier. ${ }^{10}$ Clinically, PHY is mainly used as an antidote for the treatment of central anticholinergic syndrome in the early postoperative period (eg, delirium) $)^{11-13}$ or is used among other therapeutics to improve hemodynamic and cardiac outputs ${ }^{14}$ as well as homeostatic imbalances. ${ }^{13}$ However, various experimental studies of sepsis ${ }^{15-17}$ and hemorrhagic shock ${ }^{18-21}$ demonstrated beneficial effects of prophylactical given PHY on macrocirculation, microcirculation, and survival of experimental animals. ${ }^{15-21}$

Herein, we report the beneficial effects of PHY during experimental systemic inflammation when administered therapeutically, ie, injected after an LPS infusion period of 90 minutes.

\section{Materials and methods}

\section{Chemicals and materials}

PHY salicylate (PHY, Anticholium) was a gift from Dr Franz Köhler Chemie GmbH (Bensheim, Germany). LPS (Escherichia coli, serotype O111:B4, LOT: 011M4008V) was purchased from Sigma-Aldrich (St. Louis, MO), isoflurane (Florene) from Abbott (Wiesbaden, Germany), ketamine 10\% from Ceva (Düsseldorf, Germany), lidocaine (Xylocain 1\%) from AstraZeneca (Wedel, Germany), and medical oxygen from Air Liquide (Düsseldorf, Germany). Ringer's solution and $0.9 \%$ sodium chloride solution were obtained from Fresenius Kabi (Bad Homburg, Germany) and Portex catheters $(0.58 \mathrm{~mm}$ i.d./0.96 $\mathrm{mm}$ o.d.) were purchased from Smiths Medical International (Hythe, Kent, UK).

\section{Animals}

Male Wistar rats (450-480 g) were obtained from the central animal unit of the University Hospital Essen. Animals were kept under standardized conditions of temperature $\left(22^{\circ} \mathrm{C} \pm 1^{\circ} \mathrm{C}\right)$, humidity ( $\left.55 \% \pm 5 \%\right)$, and 12-hour light/12-hour dark cycles with free access to food (ssniff-Spezialdiäten, Soest, Germany) and water. All animals received humane care according the standards of the Federation of European Laboratory Animal Science Association (FELASA). The experimental procedure has been reviewed and approved by the local Animal Care and Use Committee with the permit number Az. 84-02.04.2012.A205 (Landesamt für Natur, Umwelt und Verbraucherschutz, Nordrhein-Westfalen, Recklinghausen, Germany).

\section{Anesthesia, analgesia, surgical procedure}

Rats were anesthetized with isoflurane $(1.3 \%-2.0 \%$ in $100 \%$ medical $\mathrm{O}_{2}$ at $1.0 \mathrm{~L} / \mathrm{min}$ ) through face masks connected to a vaporizer (Isoflurane Vet. med. Vapor, Dräger, Lübeck, Germany) and received ketamine ( $50 \mathrm{mg} / \mathrm{kg}$, subcutaneously) and lidocaine (5 mg/kg, subcutaneously) for analgesia as described previously. ${ }^{8,22}$ The right Arteria femoralis and Vena femoralis were surgically prepared and cannulated with Portex catheters. At the end of the experiment, animals were sacrificed by cardiac incision under deep isoflurane anesthesia.

\section{Experimental groups}

Two series of randomized studies were conducted using overall 44 male Wistar rats: In series 1, rats received a continuous infusion of LPS over a period of 180 minutes at a rate of $7 \mathrm{~mL} /$ $\mathrm{kg} \times \mathrm{h}$ into the Vena femoralis $(0.5 \mathrm{mg} / \mathrm{kg} \times \mathrm{h})$ using a syringe pump (Perfusor-Secura FT; B. Braun, Melsungen, Germany). PHY (stock solution: $400 \mu \mathrm{g} / \mathrm{mL}$ ) was diluted with sterile $0.9 \%$ sodium chloride solution (1:28) and infused 90 minutes after starting the LPS infusion at a rate of $21 \mathrm{~mL} / \mathrm{kg} \times \mathrm{h}(50$ $\mu \mathrm{g} / \mathrm{kg}$ ) within 10 minutes. Instead of PHY, a similar volume of $0.9 \%$ sodium chloride solution was administered in nonPHY groups. Moreover, $0.9 \%$ sodium chloride solution was continuously infused starting directly after the beginning of the LPS infusion at a rate of $3 \mathrm{~mL} / \mathrm{kg} \times \mathrm{h}$ (additional volume load; Figure 1).

The following experimental groups were compared in series 1:

- $\operatorname{Sham}_{1}(\mathrm{n}=4)$ : no LPS, no PHY;

- PHY $_{1}(\mathrm{n}=4):$ no LPS, $50 \mu \mathrm{g}$ PHY $/ \mathrm{kg} \times 10$ minutes;

- $\mathrm{LPS}_{1}(\mathrm{n}=8): 0.5 \mathrm{mg} \mathrm{LPS} / \mathrm{kg} \times \mathrm{h}$, no PHY, volume load;

- $\mathrm{LPS}_{+} \mathrm{PHY}_{1}(\mathrm{n}=8): 0.5 \mathrm{mg} \mathrm{LPS} / \mathrm{kg} \times \mathrm{h}, 50 \mu \mathrm{g} \mathrm{PHY} / \mathrm{kg} \times 10$ minutes, volume load.

In series 2, LPS and PHY were given as described earlier, but without any additional volume load (Figure 1):

- $\operatorname{Sham}_{2}(\mathrm{n}=5):$ no LPS, no PHY;

- $\mathrm{PHY}_{2}(\mathrm{n}=5):$ no LPS, $50 \mu \mathrm{g}$ PHY $/ \mathrm{kg} \times 10$ minutes;

- $\operatorname{LPS}_{2}(\mathrm{n}=5): 0.5 \mathrm{mg} \mathrm{LPS} / \mathrm{kg} \times \mathrm{h}$, no PHY;

- $\mathrm{LPS} \mathrm{PHY}_{2}(\mathrm{n}=5): 0.5 \mathrm{mg} \mathrm{LPS} / \mathrm{kg} \times \mathrm{h}, 50 \mu \mathrm{g} \mathrm{PHY} / \mathrm{kg} \times 10$ minutes. 
Series 1:

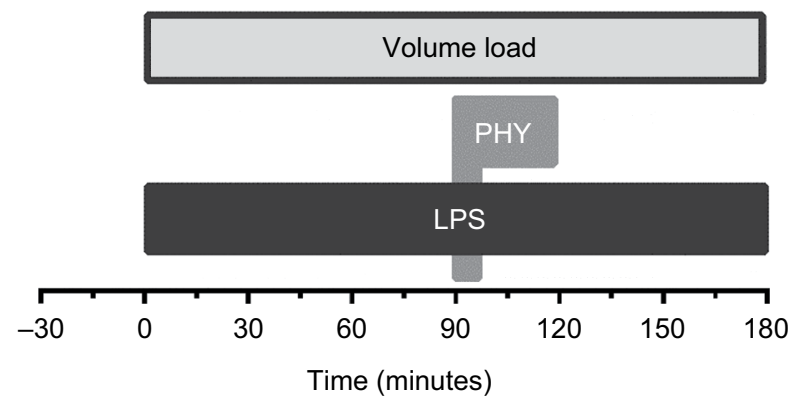

Series 2

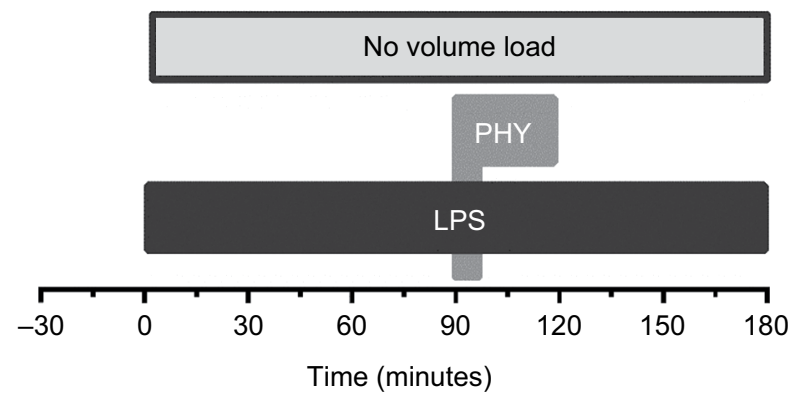

Figure I Time scale of the administration of LPS and PHY.

Notes: Catheters were inserted in femoral artery and vein before starting the LPS and PHY administration. Systemic inflammation was induced by an intravenous infusion of LPS ( $0.5 \mathrm{mg} / \mathrm{kg} \times \mathrm{h}$ over a period of 180 minutes). In series I, physiological sodium chloride solution was continuously infused starting directly after the beginning of the LPS infusion at a rate of $3 \mathrm{~mL} / \mathrm{kg} \times \mathrm{h}$. PHY (50 $\mu \mathrm{g} / \mathrm{kg} \times 10$ minutes) was infused at $T=90$ minutes after starting the LPS infusion. Blood samples were taken from the femoral artery catheter directly before starting the induction of systemic inflammation (0 minutes) and any half an hour $(30,60,90,120,150$, and 180 minutes).

Abbreviations: LPS, lipopolysaccharide; PHY, physostigmine.

\section{Assessment of vital parameters}

Systolic, diastolic, and mean arterial blood pressures (MAP) were recorded via the femoral artery catheter in 10-minute intervals. An infusion bag containing Ringer's solution was used to keep the catheter functional. Rat HRs were determined from systolic blood pressure spikes. The breathing rates were determined based on the breathing movements in 10-minute intervals. The core body temperature of the rats was continuously monitored using a rectal sensor; cooling below $37^{\circ} \mathrm{C}$ was prevented by an underlying thermostated operating table and by covering the animals with aluminum foil.

\section{Assessment of peripheral blood flow}

Microcirculation was determined using the noninvasive O2C-OXYGEN TO SEE (LEA Medizintechnik, Giessen, Germany) method, which is based on a so-called "tissue photo spectrometry". For this purpose, the venular blood flow and venular oxygen saturation in the microvessels at the left paw were measured using an FL-2 flat probe in 30-minute intervals in a depth of $5 \mathrm{~mm}$ (transcutaneous skeletal muscle).

\section{Assessment of blood and plasma parameters}

Using self-filling arterial samplers (Pico50; Radiometer Medical, Brønshøj, Denmark) containing 80 IU electrolytebalanced heparin, blood samples $(0.3 \mathrm{~mL})$ were taken from the femoral artery catheter immediately after its insertion, immediately before, and 30, 60, 90,120, 150, and 180 minutes after starting the LPS infusion. Arterial oxygen and carbon dioxide partial pressures, oxygen saturation, $\mathrm{pH}$, base excess, hemoglobin concentration, hematocrit and the concentration of the electrolytes $\mathrm{Na}^{+}, \mathrm{K}^{+}, \mathrm{Cl}^{-}$, and $\mathrm{Ca}^{2+}$, and glucose and lactate concentration were assessed with a blood gas analyzer equipped with additional electrodes (ABL 715; Radiometer, København, Denmark). For each blood sampling, animals were substituted with $0.3 \mathrm{~mL}$ of $0.9 \%$ sodium chloride solution via the femoral artery.

Heparinized blood plasma was obtained from the blood samples by centrifugation $\left(3,000 \times g\right.$ for 15 minutes at $\left.4^{\circ} \mathrm{C}\right)$. The plasma activities of lactate dehydrogenase (LDH), aspartate aminotransferase, alanine aminotransferase, and creatine kinase as well as the creatinine and urea concentration were determined with a fully automated clinical chemistry analyzer (Vitalab Selectra E; VWR International, Darmstadt, Germany) using commercially available reagents (DiaSys, Holzheim, Germany).

\section{Assessment of small intestinal tissue injury}

Immediately after the end of the experiments, the small intestine was resected, cut into 10 pieces of equal length, and rapidly transferred to Petri dishes containing ice cold buffer (140 mM NaCl, $20 \mathrm{mM}$ HEPES, pH 7.4). The severity of tissue injury was estimated by macroscopic observation of the luminal sides: ${ }^{23}$ grade $0=$ no visible alteration, grade $1=$ isolated petechiae or accumulation of blood, grade $3=$ slight local hemorrhage or accumulation of blood, and grade 9 = massive hemorrhage or accumulation of blood. The proportion of the area (in \%) of the different macroscopic damage scores was considered, and a mean value was given for the entire small intestine.

\section{Statistics}

Two series of randomized studies were conducted using overall 44 rats. The included number of rats was set to 
empirical basis. Randomization was done by lottery before the start of the studies. The data are expressed as mean values \pm standard error of the mean, and analyses were carried out using GraphPad Prism 6 (GraphPad Prism Software Inc, San Diego, CA). For all independent variables (vital, blood and plasma parameters), which were determined to have a Gaussian distribution, comparison among multiple groups was performed using one-way ANOVA followed by Dunnett's post-hoc multiple comparison test. For those that did not pass the normality test, Kruskal-Wallis test was used for the significance analysis. Differences in parameters of time were determined by repeated-measures one-way ANOVA. An a priori alpha error $P<0.05$ was considered statistically significant $(95 \% \mathrm{CI})$. Outliers were defined using box and whiskers plots.

\section{Results}

\section{Series I: effect of PHY with adequate fluid intake}

Mean arterial blood pressure (MAP) was approximately at $90 \mathrm{mmHg}$ in both rat groups Sham and PHY control during the whole experiment (Table 1). This parameter increased marginally after the administration of PHY (Figure 2A). The subsequent LPS infusion elevated MAP between 40 and 180 minutes (what was significant from 100 to 180 minutes; Figure 2A). The LPS-induced increase in MAP was enhanced by PHY directly after its administration (LPS+PHY; Figure 2A). The HR of the members of the PHY control group slightly increased from 264 to 296 beats per minute but were comparable with the Sham control group (Table 1). LPS infusion caused a significant increase in HR (Table 1; Figure 2B), which was not influenced by delayed PHY treatment.

Peripheral venular blood flow remained stable in Sham and PHY control group rats but was significantly decreased by $\sim 20 \%$ during LPS infusion, even though volume was additionally administered (Figure 2C). Decrease of peripheral blood flow by LPS was maximal at 120 minutes (reaching $80 \%$ of the initial blood flow) and persisted low until the end of the experiment. Administration of PHY significantly improved both peripheral blood flow during systemic inflammation (Figure 2C) and peripheral venular oxygen saturation (Figure 2D).

In both LPS and non-LPS group rats, arterial oxygen and carbon dioxide partial pressures as well as $\mathrm{pH}$ were not affected during experiment (Table 2). Base excess and standard bicarbonate concentration were stable for Sham and PHY control group rats, respectively. These parameters were somewhat decreased by applying LPS intravenously, whereas any effect of PHY was missing here (Table 2). The concentrations of $\mathrm{K}^{+}$, $\mathrm{Na}^{+}$and $\mathrm{Cl}^{-}$slightly increased during LPS infusion compared to non-LPS controls, whereas the concentration of $\mathrm{Ca} 2{ }^{+}$decreased. These electrolyte concentrations in control groups were not altered by administration of PHY (Table 2). The LPS infusion mediated a significant increase in plasma activities of LDH and creatine kinase (CK-NAC) as well as plasma creatinine concentration compared to both Sham and PHY control group rats (Table 3), clearly indicating tissue damage. Again any significant effect of PHY was missing here (representatively shown for CK-NAC, Figure 3A).

In non-LPS group rats, any macroscopic alterations of the small intestine were absent (Figure 4A). In contrast, significant macroscopic changes were observed in small intestines of rats treated with LPS, whereas any beneficial effect of PHY on tissue protection was again missing (Figure 4A).

\section{Series 2: effect of PHY without fluid intake}

Under hypovolemic conditions, ie, when the volume addition was avoided, LPS-induced changes in MAP, HR as well as

Table I Effects of PHY on the vital parameters ${ }^{\mathrm{a}}$ during systemic inflammation with an additional volume loading (series I)

\begin{tabular}{|c|c|c|c|c|c|}
\hline Parameters & Sham & & PHY & LPS & LPS+PHY \\
\hline & 180 minutes & 0 minutes & 180 minutes & 180 minutes & 180 minutes \\
\hline Mean arterial pressure $(\mathrm{mmHg})$ & $98 \pm 4$ & $87 \pm 5$ & $94 \pm 3$ & $106 \pm 5^{\rho=0.0247 \text { vs Sham }}$ & $118 \pm 3^{\text {NS vs LPS }}$ \\
\hline Heart rate $\left(\right.$ minute $\left.^{-1}\right)$ & $317 \pm 9$ & $278 \pm 6$ & $296 \pm 8$ & $336 \pm 6^{\rho}=0.1910$ vs Sham & $330 \pm 6^{\text {NS vs LPS }}$ \\
\hline Breathing rate (minute ${ }^{-1}$ ) & $53 \pm 3$ & $49 \pm 3$ & $48 \pm 3$ & $60 \pm 3^{\mathrm{NS} \text { vs Sham }}$ & $56 \pm 5^{N S}$ vs LPS \\
\hline Body temperature $\left({ }^{\circ} \mathrm{C}\right)$ & $38 \pm 0$ & $37 \pm 0$ & $38 \pm 0$ & $38 \pm 0^{\text {NS vs Sham }}$ & $38 \pm 0^{\text {NS vs LPS }}$ \\
\hline
\end{tabular}

Notes: Vital parameters of the groups SHAM $(n=4)$, PHY $(n=4)$, LPS $(n=8)$, and LPS+PHY $(n=8)$ are shown (mean values \pm SEM) either before the beginning of the LPS infusion (baseline, $\mathrm{T}=0$ minutes) or at $\mathrm{T}=180$ minutes. Baseline values of the Sham group were not significantly different from those of the other groups. LPS was infused at a rate of $0.5 \mathrm{mg}$ LPS $/ \mathrm{kg} \times \mathrm{h}$ over a period of 180 minutes to induce systemic inflammation in male Wistar rats. Physiological sodium chloride solution was continuously infused starting directly after the beginning of the LPS infusion at a rate of $3 \mathrm{~mL} / \mathrm{kg} \times \mathrm{h}$. PHY (50 $\mu \mathrm{g} / \mathrm{kg} \times 10$ minutes) was administered intravenously at 90 minutes after the beginning of the LPS infusion.

Abbreviations: LPS, lipopolysaccharide; PHY, physostigmine; NS, not significant; SEM, standard error of the mean. 


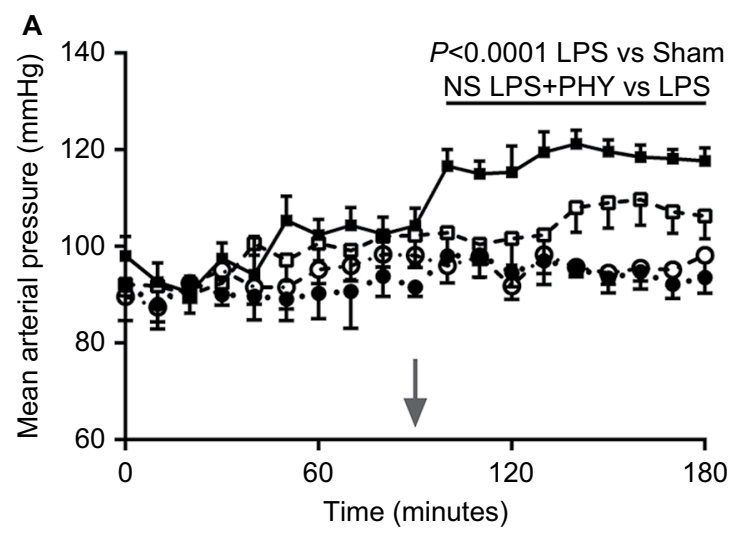

-๑ Sham $\quad \bullet$ PHY $\quad$ - $\cdot$ LPS $\quad \rightarrow$ LPS+PHY

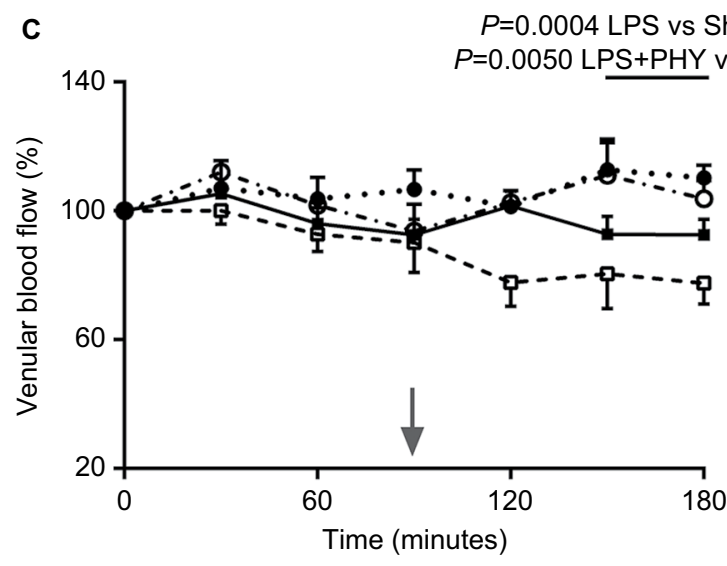

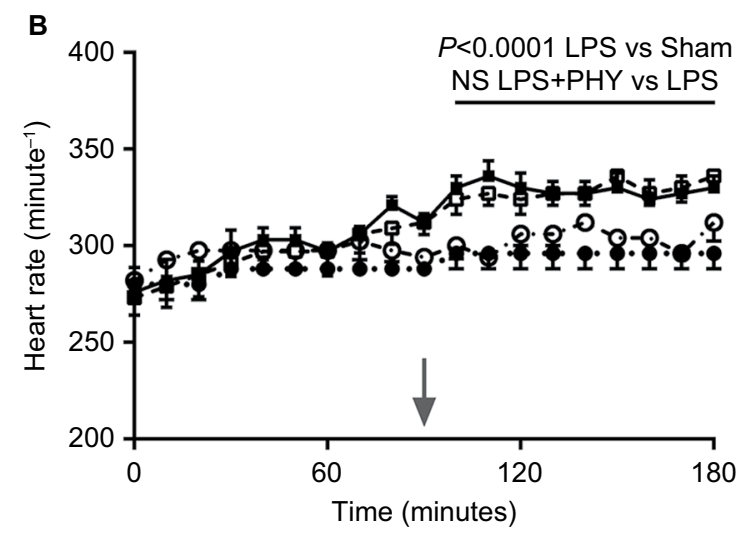

-๑ Sham : • PHY $\quad$-в. LPS $\rightarrow$ LPS+PHY

D

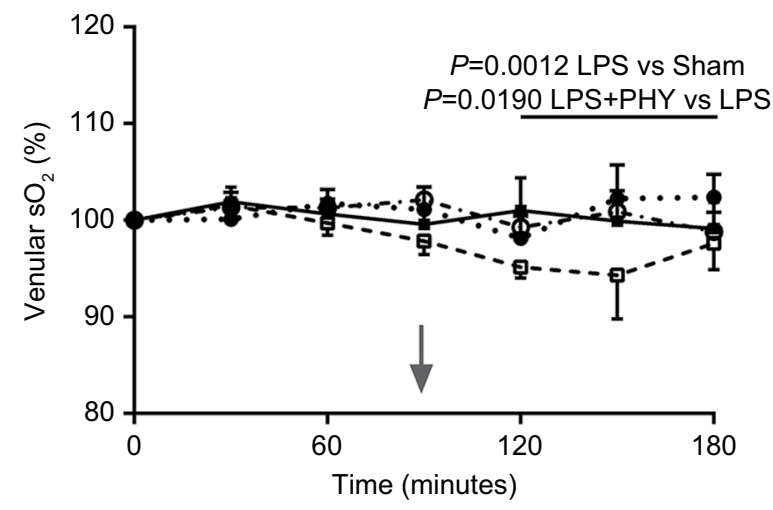

-๑ Sham .๑PHY -曰. LPS $\rightarrow$ LPS+PHY

Figure 2 Effect of $\mathrm{PHY}$ on mean arterial blood pressure $(\mathbf{A})$, heart rate $(\mathbf{B})$ as well as peripheral venular blood flow $(\mathbf{C})$ and oxygen saturation $\left(\mathrm{s} \mathrm{O}_{2}\right.$, D) during systemic inflammation, with additional volume loading (series I).

Notes: Systemic inflammation was induced by an intravenous infusion of LPS $(0.5 \mathrm{mg} / \mathrm{kg} \times \mathrm{h}$ over a period of 180 minutes). Physiological sodium chloride solution was continuously infused starting directly after the beginning of the LPS infusion at a rate of $3 \mathrm{~mL} / \mathrm{kg} \times \mathrm{h}$. PHY (50 $\mu \mathrm{g} / \mathrm{kg} \times 10$ minute) was administered intravenously at T=90 minutes after the beginning of the LPS infusion (gray arrows). Shown are mean values \pm SEM, $n=8$ animals per group ( $n=4$ for non-LPS groups).

Abbreviations: LPS, lipopolysaccharide; PHY, physostigmine; SEM, standard error of the mean.

Table 2 Effects of PHY on the blood gases and electrolytes ${ }^{a}$ during systemic inflammation with an additional volume loading (series I)

\begin{tabular}{|c|c|c|c|c|c|}
\hline \multirow[t]{2}{*}{ Parameters } & \multicolumn{2}{|l|}{ Sham } & \multirow{2}{*}{$\begin{array}{l}\text { PHY } \\
180 \text { minutes } \\
\end{array}$} & \multirow{2}{*}{\begin{tabular}{|l|} 
LPS \\
I80 minutes \\
\end{tabular}} & \multirow{2}{*}{\begin{tabular}{|l|} 
LPS + PHY \\
I80 minutes \\
\end{tabular}} \\
\hline & 180 minutes & 0 minutes & & & \\
\hline $\mathrm{pH}$ & $7.315 \pm 0.035$ & $7.24 I \pm 0.024$ & $7.308 \pm 0.033$ & $7.239 \pm 0.039 \mathrm{NS}$ vs Sham & $7.203 \pm 0.03$ I NS vs LPS $^{2}$ \\
\hline $\mathrm{pCO}_{2}(\mathrm{mmHg})$ & $43 \pm 5$ & $53 \pm 5$ & $44 \pm 4$ & $49 \pm 6^{\text {NS vs Sham }}$ & $55 \pm 4^{\text {NS vs LPS }}$ \\
\hline Base excess $(\mathrm{mmol} / \mathrm{L})$ & $-4.4 \pm 0.9$ & $-4.6 \pm 0.8$ & $-4.1 \pm 0.7$ & 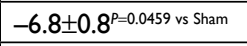 & $-6.5 \pm 0.6^{\mathrm{NS} \text { vs LPS }}$ \\
\hline $\mathrm{HCO}_{3}(\mathrm{mmol} / \mathrm{L})$ & $20.7 \pm 0.7$ & $19.8 \pm 0.6$ & $20.8 \pm 0.7$ & $18.5 \pm 0.7^{P=0.00320 \text { vs Sham }}$ & $18.5 \pm 0.6^{\mathrm{NS} \text { vs LPS }}$ \\
\hline $\mathrm{pO}_{2}(\mathrm{mmHg})$ & $299 \pm 44$ & $303 \pm 43$ & $34 I \pm 33$ & $326 \pm 2$ I NS vs Sham $^{\text {N }}$ & $305 \pm 32^{\text {NS vs LPS }}$ \\
\hline $\mathrm{K}^{+}(\mathrm{mmol} / \mathrm{L})$ & $4.3 \pm 0.1$ & $4.8 \pm 0.2$ & $4.6 \pm 0.1$ & $4.8 \pm 0 . I^{\text {NS vs Sham }}$ & $5.1 \pm 0.3^{\mathrm{NS} \text { vs LPS }}$ \\
\hline $\mathrm{Na}^{+}(\mathrm{mmol} / \mathrm{L})$ & $140 \pm 1$ & $140 \pm I$ & $140 \pm 1$ & $\mid 43 \pm I^{P=0.0574 \text { vs Sham }}$ & I $44 \pm I^{\text {NS vs LPS }}$ \\
\hline $\mathrm{Cl}^{-}(\mathrm{mmol} / \mathrm{L})$ & $114 \pm 2$ & $114 \pm 2$ & $114 \pm 2$ & $118 \pm 2^{\text {NS vs Sham }}$ & $118 \pm 2^{\text {NS vs LPS }}$ \\
\hline $\mathrm{Ca}^{2+}(\mathrm{mmol} / \mathrm{L})$ & $1.38 \pm 0.05$ & $1.39 \pm 0.05$ & $1.43 \pm 0.03$ & $1.36 \pm 0.03^{\mathrm{NS} \text { vs Sham }}$ & $1.33 \pm 0.03^{\mathrm{NS} \text { vs LPS }}$ \\
\hline
\end{tabular}

Notes: aBlood gases and electrolytes of the groups SHAM ( $n=4)$, PHY $(n=4)$, LPS $(n=8)$, and LPS + PHY $(n=8)$ are shown (mean values \pm SEM) either before the beginning of the LPS infusion (baseline, $\mathrm{T}=0$ minutes) or at $\mathrm{T}=180$ minutes. Baseline values of the Sham group were not significantly different from those of the other groups. Physiological sodium chloride solution was continuously infused starting directly after the beginning of the LPS infusion at a rate of $3 \mathrm{~mL} / \mathrm{kg} \times \mathrm{h}$. LPS was infused at a rate of $0.5 \mathrm{mg}$ LPS/ $\mathrm{kg} \times \mathrm{h}$ over a period of 180 minutes to induce systemic inflammation in male Wistar rats. PHY $(50 \mu \mathrm{gg} / \mathrm{kg} \times 10$ minutes $)$ was administered intravenously at 90 minutes after the beginning of the LPS infusion.

Abbreviations: LPS, lipopolysaccharide; PHY, physostigmine; NS, not significant; SEM, standard error of the mean. 
Table 3 Effects of PHY on the plasma enzyme activities as well as the plasma concentration of creatinine, glucose, and lactate ${ }^{a}$ during systemic inflammation with an additional volume loading (series I)

\begin{tabular}{|c|c|c|c|c|c|}
\hline \multirow[t]{2}{*}{ Parameters } & \multicolumn{2}{|l|}{ Sham } & \multirow{2}{*}{$\begin{array}{l}\text { PHY } \\
\text { I } 80 \text { minutes }\end{array}$} & \multirow{2}{*}{\begin{tabular}{|l} 
LPS \\
180 minutes
\end{tabular}} & \multirow{2}{*}{\begin{tabular}{|l} 
LPS+PHY \\
180 minutes
\end{tabular}} \\
\hline & 180 minutes & 0 minutes & & & \\
\hline Alanine aminotransferase (U/L) & $64 \pm 18$ & $45 \pm 1$ & $56 \pm 13$ & $86 \pm 9$ NS vs Sham & $102 \pm 17^{\text {NS vs LPS }}$ \\
\hline Aspartate aminotransferase (U/L) & $136 \pm 28$ & $96 \pm 15$ & $97 \pm 24$ & $177 \pm 19^{\text {NS vs Sham }}$ & $203 \pm 3$ I NS vs LPS $^{2}$ \\
\hline Lactate dehydrogenase (U/L) & $187 \pm 49$ & $20 I \pm 4 I$ & $211 \pm 33$ & $360 \pm 62^{P=0.1068 \text { vs Sham }}$ & $368 \pm 74^{\text {NS vs LPS }}$ \\
\hline Creatine kinase (U/L) & $103 \pm 19$ & $235 \pm 55$ & $144 \pm 49$ & $256 \pm 28^{P=0.0059 \text { vs Sham }}$ & $253 \pm 40^{\text {NS vs LPS }}$ \\
\hline Creatinine (mg/dL) & $0.50 \pm 0.03$ & $0.56 \pm 0.05$ & $0.64 \pm 0.07$ & $0.88 \pm 0.06^{P=0.0034 \text { vs Sham }}$ & $0.73 \pm 0.07^{\mathrm{NS} \text { vs LPS }}$ \\
\hline Glucose $(\mathrm{mg} / \mathrm{dL})$ & $149 \pm 15$ & $162 \pm 12$ & $178 \pm 13$ & $116 \pm 7^{p=0.0666 \text { vs Sham }}$ & $105 \pm 10^{\text {NS vs LPS }}$ \\
\hline Lactate $(\mathrm{mmol} / \mathrm{L})$ & $1.3 \pm 0.2$ & $1.3 \pm 0.4$ & $1.3 \pm 0.2$ & $2.0 \pm 0 . I^{P=0.0104 \text { vs Sham }}$ & $1.5 \pm 0.2^{p=0.0868 \text { vs LPS }}$ \\
\hline
\end{tabular}

Notes: ${ }^{a}$ Plasma enzyme activities as well as plasma concentration of creatinine, glucose, and lactate of the groups SHAM $(n=4)$, PHY $(n=4)$, LPS $(n=8)$, and LPS + PHY ( $=8$ ) are shown (mean values \pm SEM) either before the beginning of the LPS infusion (baseline, $T=0$ minutes) or at $T=180$ minutes. Baseline values of the Sham group were not significantly different from those of the other groups. LPS was infused at a rate of $0.5 \mathrm{mg}$ LPS/ $\mathrm{kg} \times \mathrm{h}$ over a period of I80 minutes to induce systemic inflammation in male Wistar rats. Physiological sodium chloride solution was continuously infused starting directly after the beginning of the LPS infusion at a rate of $3 \mathrm{~mL} / \mathrm{kg} \times \mathrm{h}$. PHY ( $50 \mu \mathrm{g} /$ $\mathrm{kg} \times 10$ minutes) was administered intravenously at 90 minutes after the beginning of the LPS infusion.

Abbreviations: LPS, lipopolysaccharide; PHY, physostigmine; NS, not significant; SEM, standard error of the mean.

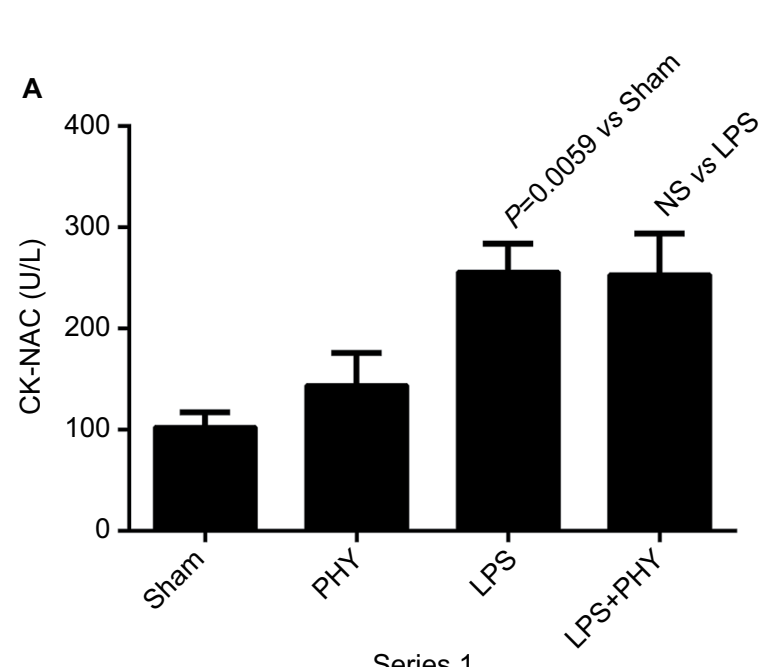

Series 1

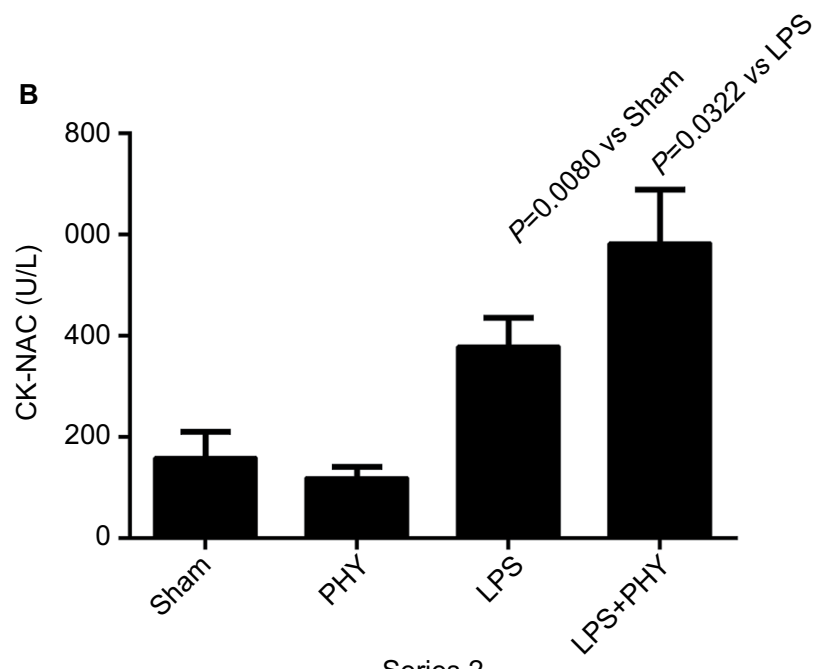

Series 2

Figure 3 Effect of PHY on final creatine kinase activity during systemic inflammation, with (series I, A) and without (series 2, B) any additional volume loading. Notes: Systemic inflammation was induced by an intravenous infusion of LPS ( $0.5 \mathrm{mg} / \mathrm{kg} \times \mathrm{h}$ over a period of 180 minutes). In series I, physiological sodium chloride solution was continuously infused starting directly after the beginning of the LPS infusion at a rate of $3 \mathrm{~mL} / \mathrm{kg} \times \mathrm{h}$. PHY (50 $\mu \mathrm{g} / \mathrm{kg} \times 10 \mathrm{minutes}) \mathrm{was}$ administered intravenously at $T=90$ minutes after the beginning of the LPS infusion. Shown are mean values $\pm S E M, n=8$ animals per group ( $n=4$ for non-LPS groups) for series $I$ and $n=5$ animals per group for series 2.

Abbreviations: CK-NAC, creatine kinase; LPS, lipopolysaccharide; PHY, physostigmine; NS, not significant; SEM, standard error of the mean.

peripheral venular blood flow, and oxygen saturation were more pronounced compared to normovolemic conditions (Series 1, Figure 5). LPS-induced increases in MAP and HR in turn were significantly elevated by PHY (Table 4, Figure 5A, B).

LPS-induced alterations in microcirculation were even worse compared to normovolemic conditions (venular blood flow was $<65 \%$ at $\mathrm{T}=90$ minutes compared to basal conditions, $P<0.0001$; venular oxygen saturation was $~ 75 \%$ at $\mathrm{T}=120$ minutes compared to basal conditions, $P=0.001$ ). Noticeably, PHY enhanced significantly the LPS-induced changes in microcirculation under hypovolemic conditions (Figure 5C, D).

LPS-dependent changes in blood gases and electrolyte concentrations were comparable to series 1 ; the additional infusion of PHY did not make any difference (Table 5). The LPS-induced increases in the plasma activity of LDH and CK-NAC were more pronounced compared to series 1 due to hypovolemic conditions (Table 6, Figure 3B). Remarkably, the LPS-induced tissue damage was significantly amplified by a delayed administration of PHY at least for monitoring CK-NAC (Figure 3B). 


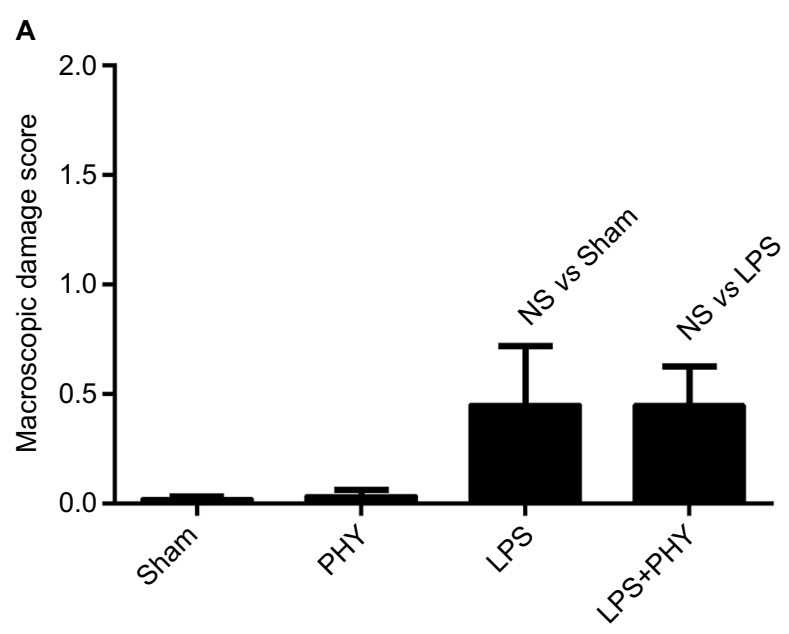

Series 1

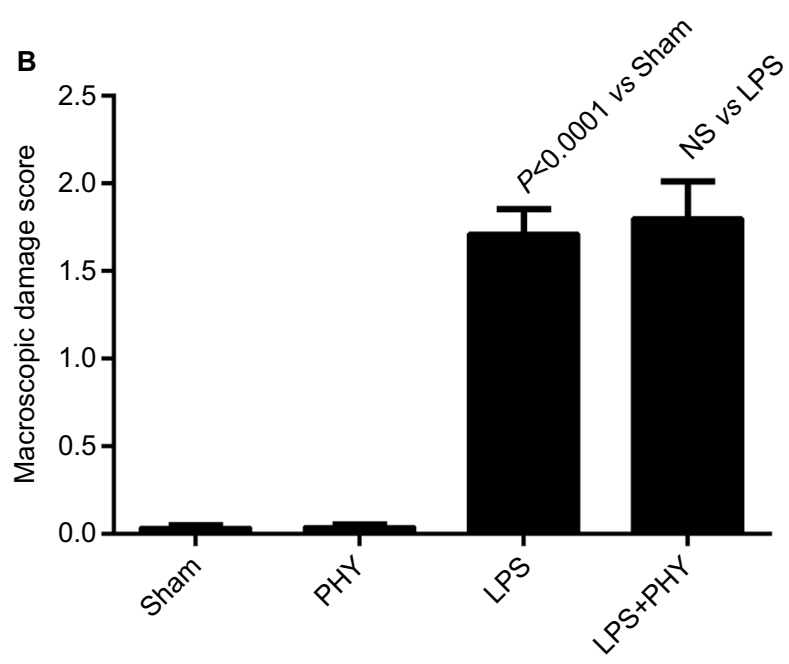

Series 2

Figure 4 Effect of PHY on small intestinal macroscopic changes during systemic inflammation, with (series I, A) and without (series 2, B) any additional volume loading. Notes: Systemic inflammation was induced by an intravenous infusion of LPS ( $0.5 \mathrm{mg} / \mathrm{kg} \times \mathrm{h}$ over a period of 180 minutes). In series I, physiological sodium chloride solution was continuously infused starting directly after the beginning of the LPS infusion at a rate of $3 \mathrm{~mL} / \mathrm{kg} \times \mathrm{h}$. PHY $(50 \mu \mathrm{g} / \mathrm{kg} \times 10 \mathrm{minutes})$ was administered intravenously at T=90 minutes after the beginning of the LPS infusion. Shown are mean values \pm SEM, $n=8$ animals per group ( $n=4$ for non-LPS groups) for series I and $n=5$ animals per group for series 2.

Abbreviations: LPS, lipopolysaccharide; PHY, physostigmine; NS, not significant; SEM, standard error of the mean.

LPS-related macroscopic changes to the small intestine were more pronounced under hypovolemic conditions compared to normovolemic conditions (Figure 4B). Again, PHY failed in mediating any beneficial effect.

\section{Discussion}

Protective effects by PHY have already been described in various experimental models of injury, among others during sepsis/systemic inflammation, ${ }^{15-17}$ hemorrhagic shock, ${ }^{18-21}$ and ischemia-reperfusion injury. ${ }^{24-26}$ However, in all these experimental animal studies, PHY has been administered in a prophylactic manner or early after the injury. A randomized, controlled clinical trial on the adjunctive use of PHY in perioperative sepsis/septic shock (treatment within 26 hours of onset of shock) recently completed recruitment of participants. ${ }^{27}$

In the present study on systemic inflammation in rats, we demonstrated distinct protective effects of PHY on hemodynamics, although the treatment was delayed as is typical for a clinical therapeutic (not prophylactic or perioperative) treatment.

The benefits of PHY in counteracting harmful actions of sepsis ${ }^{15-17}$ are primarily attributed to its direct antiinflammatory capabilities through the so-called cholinergic anti-inflammatory pathway as described by Tracey et al. ${ }^{28-30}$ Cholinesterase inhibition by PHY or its synthetic analog neostigmine has been described to improve survival and inflammation-related organ dysfunction if applied before or directly after the induction of sepsis or systemic inflammation: ${ }^{10,16}$ Hofer et al demonstrated that both PHY and neostigmine improve survival in a murine CLP model, when treatment started directly after CLP and was continued three times daily for 3 days (single dose: $80 \mu \mathrm{g} / \mathrm{kg}$ ). ${ }^{16} \mathrm{Kalb}$ et al already showed that PHY and neostigmine prevent neuroinflammation in a rat LPS model, when treatment started 5 minutes before the LPS application (single dose: $100 \mu \mathrm{g} / \mathrm{kg}) .{ }^{10}$ However, the animals were not monitored hemodynamically in these studies. However, when the intervention with PHY was delayed beyond 6 hours, any beneficial effects in either survival or organ dysfunction were lost. ${ }^{31}$ During hemorrhagic shock ${ }^{18-21}$ and partly also during ischemia-reperfusion injury, ${ }^{24,25}$ PHY improves survival by increasing blood pressure and circulating blood volume (eg, due to a general adrenergic effect/central activation of the sympathetic nervous system or due to changes in the pre- and postcapillary resistance). This hypertensive effect of PHY was to be very sensitive to the applied amount, ${ }^{24}$ but acted somewhat independently to the time point of the PHY intervention. ${ }^{21,24,32}$ Thus, even a delayed treatment with PHY improved hemodynamics during hemorrhagic shock. ${ }^{32}$ In contrast, organ dysfunctions were even worsened by a delayed PHY treatment in that study. ${ }^{32}$

In the present study, a direct anti-inflammatory effect of PHY through the cholinergic anti-inflammatory pathway ${ }^{28-30}$ 

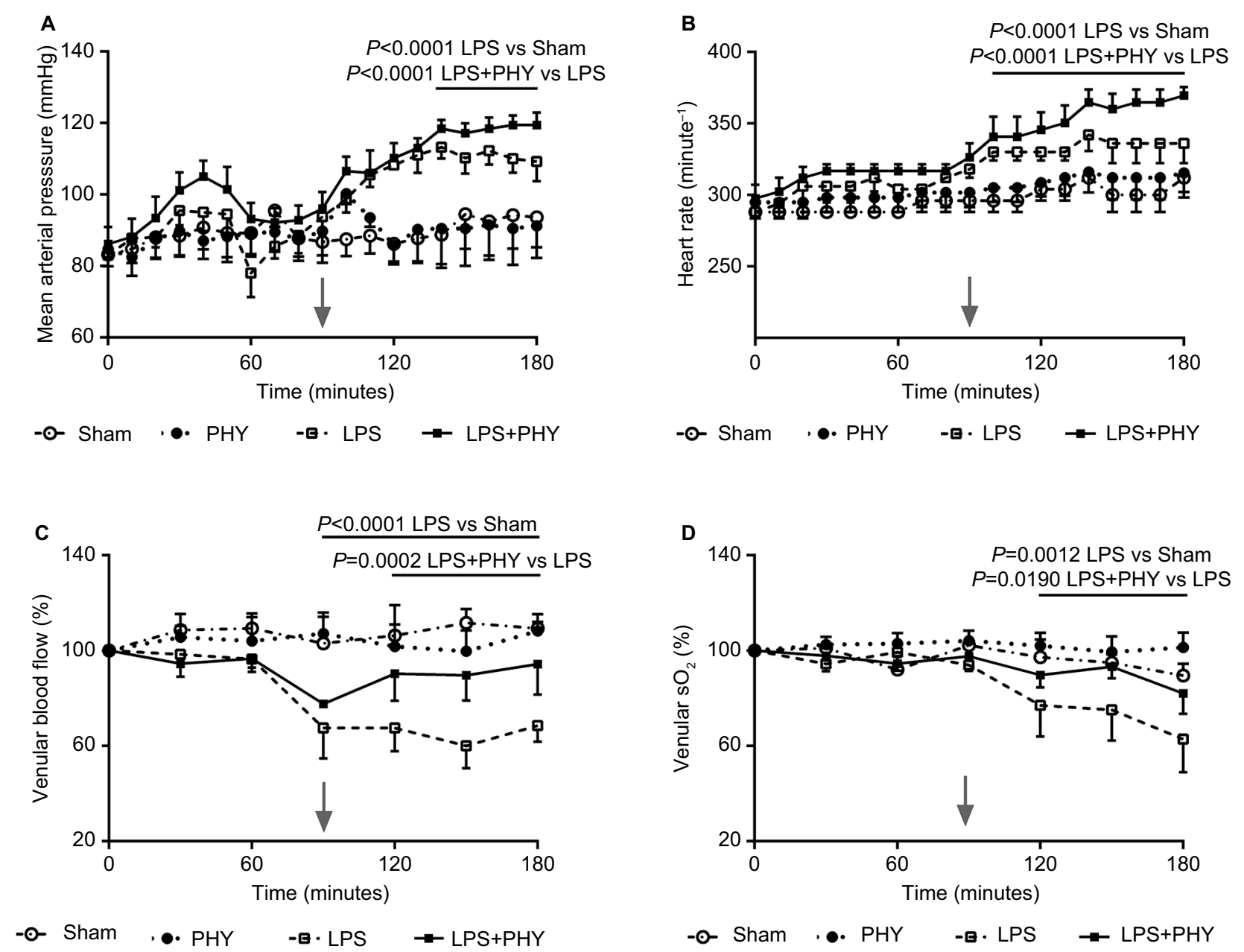

Figure 5 Effect of PHY on mean arterial blood pressure (A), heart rate (as well as peripheral venular blood flow) (C) and oxygen saturation ( $\left(\mathrm{SO}_{2}\right.$, D) during systemic inflammation, without any additional volume loading (series 2).

Notes: Systemic inflammation was induced by an intravenous infusion of LPS $(0.5 \mathrm{mg} / \mathrm{kg} \times \mathrm{h}$ over a period of 180 minutes). PHY (50 $\mu \mathrm{g} / \mathrm{kg} \times 10 \mathrm{minutes})$ was administered intravenously at $T=90$ minutes after the beginning of the LPS infusion (gray arrows). Shown are mean values \pm SEM, $n=5$ animals per group.

Abbreviations: LPS, lipopolysaccharide; PHY, physostigmine; NS, not significant; SEM, standard error of the mean.

Table 4 Effects of PHY on the vital parameters ${ }^{\text {a }}$ during systemic inflammation without any additional volume loading (series 2)

\begin{tabular}{|c|c|c|c|c|c|}
\hline \multirow[t]{2}{*}{ Parameters } & \multicolumn{2}{|l|}{ Sham } & \multirow{2}{*}{$\begin{array}{l}\text { PHY } \\
180 \text { minutes }\end{array}$} & \multirow{2}{*}{$\begin{array}{l}\text { LPS } \\
180 \text { minutes }\end{array}$} & \multirow{2}{*}{$\begin{array}{l}\text { LPS+PHY } \\
80 \text { minutes }\end{array}$} \\
\hline & 180 minutes & 0 minutes & & & \\
\hline Mean arterial pressure $(\mathrm{mmHg})$ & $94 \pm 8$ & $84 \pm 5$ & $91 \pm 9$ & $109 \pm 6^{\text {NS vs Sham }}$ & I I $9 \pm 4^{P=0.0475 \text { vs Sham }}$ \\
\hline Heart rate $\left(\right.$ minute $\left.^{-1}\right)$ & $312 \pm 14$ & $288 \pm 0$ & $315 \pm 13$ & $336 \pm 14^{\text {NS vs Sham }}$ & $369 \pm 6^{P=0.0058 \text { vs Sham }}$ \\
\hline Breathing rate $\left(\right.$ minute $\left.^{-1}\right)$ & $46 \pm 2$ & $43 \pm 1$ & $49 \pm 5$ & $54 \pm 4^{\text {NS vs Sham }}$ & $57 \pm 3^{\text {NS vs LPS }}$ \\
\hline Body temperature $\left({ }^{\circ} \mathrm{C}\right)$ & $37 \pm 0$ & $37 \pm 0$ & $38 \pm 0$ & $37 \pm 0^{\text {NS vs Sham }}$ & $38 \pm 0^{\text {NS vs LPS }}$ \\
\hline
\end{tabular}

Notes: aital parameters of the groups SHAM $(n=5)$, PHY $(n=5)$, LPS $(n=5)$, and LPS + PHY $(n=5)$ are shown (mean values \pm SEM) either before the beginning of the LPS infusion (baseline, $\mathrm{T}=0$ minutes) or at $\mathrm{T}=180$ minute. Baseline values of the Sham group were not significantly different from those of the other groups. LPS was infused at a rate of $0.5 \mathrm{mg} \mathrm{LPS} / \mathrm{kg} \times \mathrm{h}$ over a period of 180 minutes to induce systemic inflammation in male Wistar rats. PHY ( $50 \mathrm{\mu g} / \mathrm{kg} \times 10$ minute) was administered intravenously at 90 minutes after the beginning of the LPS infusion.

Abbreviations: LPS, lipopolysaccharide; PHY, physostigmine; NS, not significant; SEM, standard error of the mean.

is rather unlikely, because PHY was administered 90 minutes after the onset of LPS-induced sepsis. Referring to our earlier studies, ${ }^{8,22}$ the activation of nuclear factor kappa B and the release of tumor necrosis factor alpha are maximal within the first 60 minutes after the beginning of the LPS infusion. Thus, in the present study, PHY was applied in a therapeutic manner because it was offered at least 30 minutes after the cytokines have reached their maximal levels. ${ }^{22}$ In accord, 
Table 5 Effects of PHY on the blood gases and electrolytes ${ }^{\mathrm{a}}$ during systemic inflammation without any additional volume loading (series 2)

\begin{tabular}{|c|c|c|c|c|c|}
\hline Parameters & Sham & & PHY & LPS & LPS+PHY \\
\hline & 180 minutes & 0 minutes & 180 minutes & 180 minutes & 180 minutes \\
\hline $\mathrm{pH}$ & $7.274 \pm 0.018$ & $7.297 \pm 0.017$ & $7.319 \pm 0.043$ & $7.284 \pm 0.038^{\text {NS vs Sham }}$ & $7.347 \pm 0.038^{\mathrm{NS} \text { vs LPS }}$ \\
\hline $\mathrm{pCO}_{2}(\mathrm{mmHg})$ & $40 \pm 5$ & $44 \pm 4$ & $40 \pm 3$ & $38 \pm 5^{\text {NS vs Sham }}$ & $3 I \pm 3^{\text {NS vs LPS }}$ \\
\hline Base excess $(\mathrm{mmol} / \mathrm{L})$ & $-5.1 \pm 0.8$ & $-4.8 \pm 0.6$ & $-5.4 \pm 1.5$ & $-8 . I \pm I .2^{P=0.0723 \text { vs Sham }}$ & $-8.5 \pm I . I^{\text {NS vs LPS }}$ \\
\hline $\mathrm{HCO}_{3}(\mathrm{mmol} / \mathrm{L})$ & $19.5 \pm 0.8$ & $20.1 \pm 0.4$ & $20.0 \pm 1.3$ & $17.7 \pm 0.9^{\mathrm{NS} \text { vs Sham }}$ & $17.8 \pm 0.9^{\mathrm{NS} \text { vs LPS }}$ \\
\hline $\mathrm{pO}_{2}(\mathrm{mmHg})$ & $35 I \pm 10$ & $358 \pm 21$ & $310 \pm 15$ & $272 \pm 21^{P=0.0174 \text { vs Sham }}$ & $297 \pm 13^{\text {NS vs LPS }}$ \\
\hline $\mathrm{K}^{+}(\mathrm{mmol} / \mathrm{L})$ & $4.5 \pm 0.2$ & $4.6 \pm 0.2$ & $4.6 \pm 0.1$ & $4.8 \pm 0.3^{\mathrm{NS} \text { vs Sham }}$ & $4.7 \pm 0.3^{\mathrm{NS} \text { vs LPS }}$ \\
\hline $\mathrm{Na}^{+}(\mathrm{mmol} / \mathrm{L})$ & $139 \pm 3$ & $14 I \pm 1$ & $140 \pm I$ & $\mid 4 I \pm I^{\text {NS vs Sham }}$ & $|4| \pm I^{\text {NS vs LPS }}$ \\
\hline $\mathrm{Cl}^{-}(\mathrm{mmol} / \mathrm{L})$ & $116 \pm 2$ & $114 \pm 2$ & $115 \pm 3$ & $119 \pm 3^{\text {NS vs Sham }}$ & $118 \pm 2^{\text {NS vs LPS }}$ \\
\hline $\mathrm{Ca}^{2+}(\mathrm{mmol} / \mathrm{L})$ & $1.40 \pm 0.12$ & $1.40 \pm 0.08$ & $1.48 \pm 0.03$ & $1.38 \pm 0.06^{\mathrm{NS} v \text { v Sham }}$ & $\mathrm{I} .34 \pm 0.0 \mathrm{I}^{\mathrm{NS} \text { vs LPS }}$ \\
\hline
\end{tabular}

Notes: aBlood gases and electrolytes of the groups SHAM $(n=5)$, PHY $(n=5)$, LPS $(n=5)$, and LPS + PHY $(n=5)$ are shown (mean values \pm SEM) either before the beginning of the LPS infusion (baseline, $T=0$ minutes) or at $T=180$ minutes. Baseline values of the Sham group were not significantly different from those of the other groups. LPS was infused at a rate of $0.5 \mathrm{mg} \mathrm{LPS} / \mathrm{kg} \times \mathrm{h}$ over a period of 180 minutes to induce systemic inflammation in male Wistar rats. PHY (50 $\mu \mathrm{g} / \mathrm{kg} \times 10 \mathrm{minutes})$ was administered intravenously at 90 minutes after the beginning of the LPS infusion.

Abbreviations: LPS, lipopolysaccharide; PHY, physostigmine; NS, not significant; SEM, standard error of the mean.

Table 6 Effects of PHY on the plasma enzyme activities as well as the plasma concentration of creatinine, glucose, and lactate ${ }^{\mathrm{a}}$ during systemic inflammation without any additional volume loading (series 2 )

\begin{tabular}{|c|c|c|c|c|c|}
\hline \multirow[t]{2}{*}{ Parameters } & \multicolumn{2}{|l|}{ Sham } & \multirow{2}{*}{$\begin{array}{l}\text { PHY } \\
180 \text { minutes }\end{array}$} & \multirow{2}{*}{$\begin{array}{l}\text { LPS } \\
180 \text { minutes }\end{array}$} & \multirow{2}{*}{$\begin{array}{l}\text { LPS+PHY } \\
80 \text { minutes }\end{array}$} \\
\hline & 180 minutes & 0 minute & & & \\
\hline Alanine aminotransferase (U/L) & $68 \pm 18$ & $54 \pm 9$ & $111 \pm 15$ & $|32 \pm 3|^{P=0.0140 \text { vs Sham }}$ & $134 \pm 15^{\text {NS vs LPS }}$ \\
\hline Aspartate aminotransferase (U/L) & $109 \pm 12$ & $111 \pm 38$ & $138 \pm 13$ & 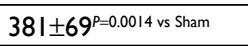 & $357 \pm 22^{\text {NS vs LPS }}$ \\
\hline Lactate dehydrogenase (U/L) & $311 \pm 86$ & $209 \pm 23$ & $282 \pm 73$ & $1097 \pm\left. 23\right|^{P=0.011 I \text { vs Sham }}$ & $1225 \pm 290^{\text {NS vs LPS }}$ \\
\hline Creatine kinase (U/L) & $|58 \pm 78|$ & $299 \pm 66$ & $119 \pm 22$ & $378 \pm 57^{\mathrm{P}=0.0080 \text { vs Sham }}$ & $583 \pm 106^{P=0.0322 \text { vs LPS }}$ \\
\hline Creatinine (mg/dL) & $1.00 \pm 0.12$ & $0.75 \pm 0.22$ & $0.93 \pm 0.08$ & $1.10 \pm 0.02^{\mathrm{NS} \text { vs Sham }}$ & $1.37 \pm 0.14^{P=0.0492 \text { vs LPS }}$ \\
\hline Glucose (mg/dL) & $158 \pm 10$ & $168 \pm 11$ & $157 \pm||$ & $1 / 7 \pm 18^{p=0.0247 \text { vs Sham }}$ & $84 \pm 14^{\text {NS vs LPS }}$ \\
\hline Lactate $(\mathrm{mmol} / \mathrm{L})$ & $1.1 \pm 0.1$ & $1.1 \pm 0.1$ & $1.3 \pm 0.3$ & $2.5 \pm 0.4^{P=0.0130 \text { vs Sham }}$ & $2.7 \pm 0.2^{\mathrm{NS} \text { vs LPS }}$ \\
\hline
\end{tabular}

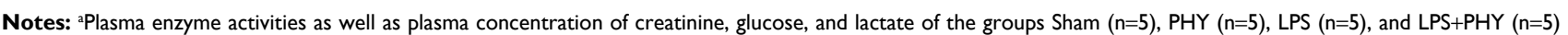
are shown (mean values \pm SEM) either before the beginning of the LPS infusion (baseline, $T=0$ minutes) or at $T=180$ minutes. Baseline values of the Sham group were not significantly different from those of the other groups. LPS was infused at a rate of $0.5 \mathrm{mg}$ LPS $/ \mathrm{kg} \times \mathrm{h}$ over a period of 180 minutes to induce systemic inflammation in male Wistar rats. PHY (50 $\mu \mathrm{g} / \mathrm{kg} \times 10$ minutes) was administered intravenously at 90 minutes after the beginning of the LPS infusion.

Abbreviations: LPS, lipopolysaccharide; PHY, physostigmine; NS, not significant; SEM, standard error of the mean.

peripheral blood flow was already maximally decreased by LPS after a period of 90 minutes, whereas blood pressure and HR were increased. ${ }^{8}$

With the applied protocol, PHY neither improved the LPS-induced tissue damage nor prevented from alterations in blood gases, electrolyte homeostasis, and glucose metabolism induced by LPS. In line with these observations, protective effects on tissue damage were less expected, after Fodale and Santamaria already criticized, that cholinesterase inhibition (by PHY) failed to improve survival and tissue injury when treatment was delayed. ${ }^{31}$ Nevertheless, the delayed treatment with PHY during systemic inflammation specifically improved hemodynamics in macro- and microcirculation (vide supra). In course of an improved perfusion, plasma lactate level was improved by PHY as well. Furthermore, we found LPS-induced tissue damage to be increased by delayed PHY treatment if sufficient fluid intake/volume load is not guaranteed (series 2). As early as 1981, Hoffman and McElroy already pointed out that PHY can be used in patients after tricyclic antidepressants overdose only with sufficient volume replacement. ${ }^{33}$

Using in vitro experiments on rat aortic rings, Zhou et al demonstrated that lower concentrations of PHY (20-40 $\mu \mathrm{g} /$ $\mathrm{kg}$ ) produced contraction of rat aortic rings, whereas higher concentrations $\left(70-100 \mu \mathrm{g} / \mathrm{kg}\right.$ ) produced relaxation. ${ }^{17}$ They further found that a recovery from LPS-induced disturbances of the (intestinal) microcirculation by PHY treatment "may be related to its direct effects on blood vessels tension". ${ }^{17}$ Such a dual effect has also been demonstrated for neostigmine - the synthetic analog of PHY: ${ }^{34}$ Using isolated, spontaneously beating guinea pig, right atrial preparations neostigmine decreased the spontaneously beating rate in a concentration-dependent manner. Endou et al concluded that low concentrations of 
neostigmine may stimulate the muscarinic acetylcholine receptors directly, and that at higher concentrations, neostigmine may act as an antimuscarinic agent. ${ }^{34}$ This may explain why PHY or neostigmine doses between 30 and $100 \mu \mathrm{g} / \mathrm{kg}$ are predominantly protective, ${ }^{15-21,24-26}$ whereas higher (cumulative) doses of PHY or neostigmine (300 $\mu \mathrm{g} / \mathrm{kg}$ and more) worsened the outcome from ischemia-reperfusion ${ }^{35}$ or sepsis/ systemic inflammation ${ }^{31,36}$ and even caused a state of shock. ${ }^{37}$

In conclusion, PHY improves hemodynamics in macroand microcirculation during systemic inflammation in rats, although the treatment was delayed. At a lower dosage (single dose up to $50 \mu \mathrm{g} / \mathrm{kg}$ ), it may play a potential role in septic patients with microcirculatory dysfunction and hypotension, provided that a sufficient fluid intake is guaranteed.

\section{Acknowledgments}

We would like to thank Mr Falk Kähler and Mr Alexander Vollmer from the Institute of Physiological Chemistry, University Hospital Essen, Essen, Germany, for their excellent technical assistance. This work was supported by Dr Franz Köhler Chemie GmbH, Bensheim, Germany. Dr Franz Köhler Chemie GmbH was not involved in the conception and design of the experimental protocol.

\section{Author contributions}

KEN designed the study, interpreted the data, and prepared the manuscript. JJ acquired and analyzed the data. RV and MK helped to interpret the data. MK supervised the study. All authors contributed toward data analysis, drafting and critically revising the paper, gave final approval of the version to be published, and agree to be accountable for all aspects of the work.

\section{Disclosure}

The authors report no conflicts of interest in this work.

\section{References}

1. Brunkhorst FM. Epidemiology, economy and practice - results of the German study on prevalence by the competence network sepsis (SepNet). Anasthesiol Intensivmed Notfallmed Schmerzther. 2006;41(1):43-44.

2. Trampuz A, Zimmerli W. Pathogenesis und therapie der sepsis. Schweiz Med Forum. 2003;35:811-818.

3. Vincent JL, Serrano EC, Dimoula A. Current management of sepsis in critically ill adult patients. Expert Rev Anti Infect Ther. 2011;9(7):847-856.

4. Rhodes A, Evans LE, Alhazzani W, et al. Surviving sepsis campaign: international guidelines for management of sepsis and septic shock: 2016. Intensive Care Med. 2017;43(3):304-377.

5. Seymour CW, Liu VX, Iwashyna TJ, et al. Assessment of clinical criteria for sepsis: for the third international consensus definitions for sepsis and septic shock (Sepsis-3). JAMA. 2016;315(8):762-774.

6. Poli-de-Figueiredo LF, Garrido AG, Nakagawa N, Sannomiya P. Experimental models of sepsis and their clinical relevance. Shock. 2008;30 (Suppl 1):53-59.
7. Remick DG, Ward PA. Evaluation of endotoxin models for the study of sepsis. Shock. 2005;24(Suppl 1):7-11.

8. Effenberger-Neidnicht K, Al Nator M, Brencher L, Oude Lansink M, de Groot H. Prevention of endotoxin-induced hypotension in rats by the circadian hormone melatonin. Infection. 2013;41:S11-S12.

9. Zhao B, Moochhala SM, Tham SY. Biologically active components of Physostigma venenosum. J Chromatogr B Analyt Technol Biomed Life Sci. 2004;812(1-2):183-192.

10. Kalb A, von Haefen C, Sifringer M, et al. Acetylcholinesterase inhibitors reduce neuroinflammation and -degeneration in the cortex and hippocampus of a surgery stress rat model. PLoS One. 2013;8(5):e62679.

11. Betten DP, Vohra RB, Cook MD, Matteucci MJ, Clark RF. Antidote use in the critically ill poisoned patient. J Intensive Care Med. 2006;21(5): 255-277.

12. Stilson M, Kelly K, Suchard J. Physostigmine as an antidote. Cal J Emerg Med. 2001;2(4):47-48.

13. Zielmann $\mathrm{S}$, Petrow H, Walther P, Henze T. Intensive care of delirium syndromes. Anaesthesiol Reanim. 2003;28(1):8-12.

14. Nilsson E, Meretoja OA, Neuvonen P. Hemodynamic responses to physostigmine in patients with a drug overdose. Anesth Analg. 1983;62(10):885-888.

15. Peter C, Schmidt K, Hofer S, et al. Effects of physostigmine on microcirculatory alterations during experimental endotoxemia. Shock. 2010;33(4):405-411.

16. Hofer S, Eisenbach C, Lukic IK, et al. Pharmacologic cholinesterase inhibition improves survival in experimental sepsis. Crit Care Med. 2008;36(2):404-408.

17. Zhou J, Pavlovic D, Rüb J, et al. Physostigmine reverses disturbances of the intestinal microcirculation during experimental endotoxemia. Clin Hemorheol Microcirc. 2014;56(3):273-284.

18. Zunić G, Savić J, Prostran M, Varagić V, Vujnov S, Todorović Z. The effect of physostigmine on acid-base status in arterial and venous blood of anaesthetized rabbits following hypovolemic shock. Gen Pharmacol. 1995;26(2):291-295.

19. Savić J, Varagić VM, Prokić D, et al. The life-saving effect of physostigmine in haemorrhagic shock. Resuscitation. 1991;21(1):57-60.

20. Guarini S, Tagliavini S, Ferrari W, Bertolini A. Reversal of haemorrhagic shock in rats by cholinomimetic drugs. Br J Pharmacol. 1989;98(1): $218-224$.

21. Mathis KW, Sulzer J, Molina PE. Systemic administration of a centrally acting acetylcholinesterase inhibitor improves outcome from hemorrhagic shock during acute alcohol intoxication. Shock. 2010;34(2):162-168.

22. Effenberger-Neidnicht K, Brencher L, Broecker-Preuss M, Hamburger T, Petrat F, de Groot H. Immune stimulation by exogenous melatonin during experimental endotoxemia. Inflammation. 2014;37(3):738-744.

23. Petrat F, Swoboda S, de Groot H, Schmitz KJ. Quantification of ischemia-reperfusion injury to the small intestine using a macroscopic score. J Invest Surg. 2010;23(4):208-217.

24. Verhaegh R, Petrat F, de Groot H. Attenuation of intestinal ischemic injury and shock by physostigmine. J Surg Res. 2015;194(2):405-414.

25. Scremin OU, Scremin AM. Physostigmine induced reversal of ischemia following acute middle cerebral artery occlusion in the rat. Stroke. 1986;17(5):1004-1009.

26. Kutsuna S, Tsuruta R, Fujita M, et al. Cholinergic agonist physostigmine suppresses excessive superoxide anion radical generation in blood, oxidative stress, early inflammation, and endothelial injury in rats with forebrain ischemia/reperfusion. Brain Res. 2010;1313: 242-249.

27. Zimmermann JB, Pinder N, Bruckner T, et al. Adjunctive use of physostigmine salicylate (Anticholium ${ }^{\circledR}$ ) in perioperative sepsis and septic shock: study protocol for a randomized, double-blind, placebo-controlled, monocentric trial (Anticholium ${ }^{\circledR}$ per Se). Trials. 2017;18(1):530.

28. Bernik TR, Friedman SG, Ochani M, et al. Cholinergic antiinflammatory pathway inhibition of tumor necrosis factor during ischemia reperfusion. J Vasc Surg. 2002;36(6):1231-1236. 
29. Pavlov VA, Wang H, Czura CJ, Friedman SG, Tracey KJ. The cholinergic anti-inflammatory pathway: a missing link in neuroimmunomodulation. Mol Med. 2003;9(5-8):125-134.

30. Tracey KJ. Physiology and immunology of the cholinergic antiinflammatory pathway. J Clin Invest. 2007;117(2):289-296.

31. Fodale V, Santamaria LB. Cholinesterase inhibitors improve survival in experimental sepsis: a new way to activate the cholinergic antiinflammatory pathway. Crit Care Med. 2008;36(2):622-623.

32. Sulzer JK, Molina PE. Delayed resuscitation with physostigmine increases end organ damage in alcohol intoxicated rats. Shock. 2011;35(1):74-79.

33. Hoffman JR, Mcelroy CR. Bicarbonate therapy for dysrhythmia and hypotension in tricyclic antidepressant overdose. West $\mathrm{J} \mathrm{Med.}$ 1981;134(1):60-64.
34. Endou M, Tanito Y, Okumura F. A comparison between chronotropic effects of neostigmine and edrophonium in isolated guinea pig right atrium. J Pharmacol Exp Ther. 1997;282(3):1480-1486.

35. Schultz JA, Hoffman WE, Albrecht RF. Sympathetic stimulation with physostigmine worsens outcome from incomplete brain ischemia in rats. Anesthesiology. 1993;79(1):114-121.

36. Akinci SB, Ulu N, Yondem OZ, et al. Effect of neostigmine on organ injury in murine endotoxemia: missing facts about the cholinergic antiinflammatory pathway. World J Surg. 2005;29(11): 1483-1489.

37. Spitzer JJ. Myocardial metabolism during acute shock induced by hemorrhage, endotoxin, or physostigmine infusion. Myocardial Metabolism. 1974;3:161-167.
Journal of Inflammation Research

\section{Publish your work in this journal}

The Journal of Inflammation Research is an international, peer-reviewed open access journal that welcomes laboratory and clinical findings on the molecular basis, cell biology and pharmacology of inflammation including original research, reviews, symposium reports, hypothesis formation and commentaries on: acute/chronic inflammation; mediators of inflammation

\section{Dovepress}

cellular processes; molecular mechanisms; pharmacology and novel anti-inflammatory drugs; clinical conditions involving inflammation. The manuscript management system is completely online and includes a very quick and fair peer-review system. Visit http://www.dove press.com/testimonials.php to read real quotes from published authors.

Submit your manuscript here: https://www.dovepress.com/journal-of-inflammation-research-journal 